\title{
ON AN EXTENSIVE SERIES OF MILK ANALYSES MADE DURING THE YEAR 1882.
}

By Dr. P. VIETH, F.C.S.

Read before the Society of Public Analysts on the 14th February, 1883.

THe communications I am going to bring before you relate to a great number of milk analyses, executed during the last year in connection with the controlling system carried on by the Aylesbury Dairy Company. This system is a very exlensive one, and does not begin only after the milk has been received on the company's premises, but at the very source of the milk-on the farms.

It would be going too far to dwell upon all the details at any length, and, therefore, I will sketch only the most essential points. After the milk has arrived on the company's premises the contents of each churn are thoroughly mixed and tested with thermometer and lactometer, temperature and specific gravity being recorded. In case a divergence to any considerable extent from the figures usually found should be noticed, the milk is not sent out, at least, not before its genuineness is proved. At least one sample of milk from each farmer is analysed daily or every other day, care being taken to get alternately samples of morning and evening milk. Before the milk leaves the jard other samples are drawn from the delivery churns, tested with the lactometer and kept until after all the men have returned from their rounds, so that these samples may be compared with samples taken in the streets by the company's own inspectors from the men in charge of the rounds, and for the purpose to control the latter. 
The samples thus taken by the inspectors are analysed, and these samples in connection with those taken of the milk on its arrival form the greatest part of all the samples analysed. The total number of all the analyses made during the year 1882 is 12,430. Of this number 12,349 are milk samples. Among the latter there are 9,190 samples taken on arrival of the milk in the dairy and before it ras sent out, and 2,948 samples taken by the company's own inspectors in the streets during delivery of the milk to the customers.

As some of the rounds go rather far and the delivery of the milk occupies several hours, some alteration in the distribution of the lat might be expected, and in some cases could be proved. But there was never a difference of any importance in the average composition of the two kinds of milk samples. except in a case I brought before you at the last November meeting.

Regarding the analytical method applied, I refer to the paper I read before this Snciety in the month of March last year, and repeat only, that the total solids are ascertained by evaporating 5 c.c. of mills in a shallow platinum disb, which is kept on a steam-bath for three hours and in an air-bath at a temperature of from $95^{\circ}$ to $100^{\circ} \mathrm{C}$ for the same length of time, whilst the fat is determined by means of Marchand's lactobutyrometer, an

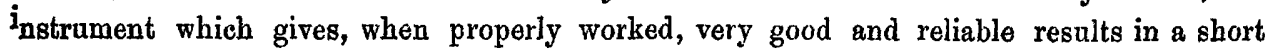
time. After having used the said instrument very extensively for more than two years, I think it exceedingly suitable for the milk control. Chemists, who have made and published experiments with the lactobutyrometer differ in their opinions as regards working the instrument in one point, viz., whether it is better to prevent the precipitation of the casein by adding a few drops of a potassium bydrate solution, or whether it is to be preferred not to do so, perhaps even to precipitate the casein by adding some acetic acid. My experience on the point is this, that during the time the cows are housed the fat rises better if some potassium hydrate be used, whilst during the warmer part of the year better results are obtained, and in a shorter time, without the addition of potash. I have reason to believe that this different behaviour of the milk has something to do with the swollen state in which the casein is believed to be present in milk. By practical experiences it appears that the degree of the swollen state of the casein is influenced to a certain extent by the conditions nuder which the cows are kept and how they are fed.

I shall give you now the monthly averages for the composition of samples taken of the milk when received :-

\begin{tabular}{|c|c|c|c|c|c|c|c|c|c|}
\hline \multirow{2}{*}{$\begin{array}{c}1832 . \\
\text { January }\end{array}$} & \multirow[b]{2}{*}{$\bullet$} & \multirow[b]{2}{*}{ 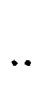 } & \multicolumn{2}{|c|}{ Specific Grarity. } & \multicolumn{2}{|c|}{ otal Solids. } & \multirow{2}{*}{$\begin{array}{l}\text { Fat. } \\
3 \cdot 36\end{array}$} & \multicolumn{2}{|c|}{ Solids not fat. } \\
\hline & & & .. 1.0317 & .. & $12 \cdot 89$ & . & & .. & $9 \cdot 53$ \\
\hline February & .. & .. & .. 10320 & .. & $12 \cdot 76$ & .. & $3 \cdot 26$ & .. & $9 \cdot 50$ \\
\hline March .. & .. & .. & .. 1.0320 & .. & $12 \cdot 73$ & .. & $3 \cdot 16$ & .. & $9 \cdot 57$ \\
\hline April $\quad$. & .. & .. & .. 1.0320 & -. & $12 \cdot 96$ & .. & $3 \cdot 40$ & .. & $9 \cdot 56$ \\
\hline May & .. & .. & .. $1 \cdot 0321$ & .. & $12 \cdot 95$ & .. & $3 \cdot 40$ & $\cdots$ & $9 \cdot 55$ \\
\hline June & $\cdots$ & .. & .. 10317 & $\cdots$ & 1296 & .. & $3 \cdot 55$ & $\cdots$ & $9 \cdot 41$ \\
\hline July & .. & .. & .. 1.0316 & .. & $12 \cdot 99$ & .. & $3 \cdot 57$ & .. & 942 \\
\hline August ... & .• & .. & .. 1.0315 & .. & $13 \cdot 04$ & .. & 360 & .. & $9 \cdot 44$ \\
\hline September & .. & .. & .. 1.0319 & .. & $13 \cdot 12$ & .. & 360 & .. & $9 \cdot 52$ \\
\hline October... & .. & .. & .. 1.0321 & .. & $13 \cdot 36$ & .. & $3 \cdot 75$ & .. & $9 \cdot 61$ \\
\hline November & .. & . & .. 1.0321 & $\cdot$ & $13 \cdot 40$ & .. & $3 \cdot 82$ & .. & $9 \cdot 58$ \\
\hline December & .. & .. & .. 1.0319 & $\cdots$ & $13 \cdot 14$ & $\cdots$ & $3 \cdot 75$ & .. & $9 \cdot 39$ \\
\hline Yo & $\nabla$ & & 3819 & $\cdots$ & $13 \cdot 08$ & .. & $8 \cdot 62$ & 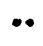 & $9 \cdot 61$ \\
\hline
\end{tabular}


By this table it appears that the milk contained the lowest amount of total solids and of fat in the month of March, the highest in the month of November. The extreme figures for total solids are 12.73 and 13.40 , for fat 3.16 and 3.82 per, cent. The solids not fat fluctuate in very narrow limitg only, the lowest figure being 9.39 and the highest 961 per cent. The specific gravity is also very constant. The yearly average of the total solids is 0.23 per cent. higher than that of the year 1881 .

Interesting as the figures in Table I., showing the average composition of the milk from all the contractors, may be, they do not allow us to draw any conclusion regarding the composition of the milk supplied by the individual farmers, and in this respect the following Tables II. and III. may prove to be of greater inportance. They show for each month the average composition of the milk delivered from those farmers being first and last on the list.

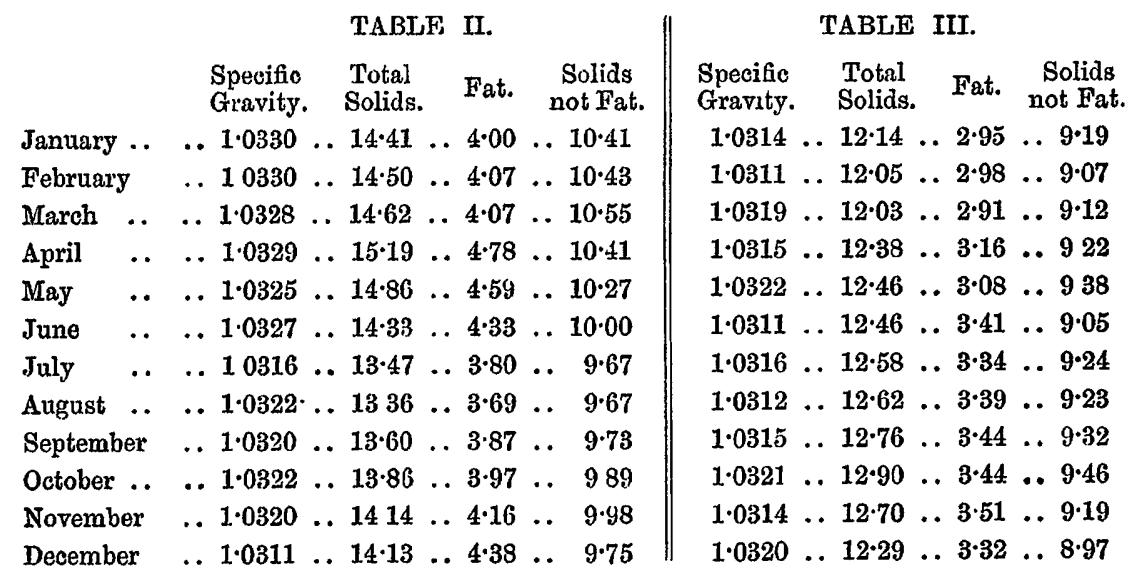

The total solids fell in proportionately very few cases only below 12 per cent. ; fat was found to amount very seldom less than 3 per cent. ; the solids not fat kept generally above 9, but in some instances came down to 8.8 per cent.

I must insist upon my opinion that an amount of solids not fat below 9 per cent. does not always mean that the milk has been watered, provided total solids and fat to be exactly ascertained.

In my laboratory, the specific gravity is determined of about $\mathbf{2 5 0}$ milk samples dailyof course, by means of the lactometer. In far the most cases the specific gravity is found to be between 1.030 and 1.033 , sometimes it rose to 1.034 , bat scarcely fell below 1.030 , and, in fact, wo look with suspicion at a milk with a lower specific gravity.

Summing up the experiences collected by another year's work in a very special direc. tion, I come to about the same conclusions, which $I$, for the first time, put before you one year ago. I think the standard figures for fat and solids not fat ought to be altered, the former being raised so much as 0.25 per cent., the latter being reduced to the same extent, so that the limits for genuine mills would stand as follows:-Total solids, 11.50 ; fat, 2.75; and solids not fat, 8.75 per cent. I am fully aware of the disadvantages induced by the alteration of a stindard after it has been once fixed, but these disadrantages will have to be faced as soon as the advantages are found to be greater. I do not doubt that the Society's standard was right, and is right, if the milk analysis is executed according to the 
method fixed by the Society. But since some analysts do not dry the solids on the waterbath only, but additionally in the air-bath, and extract the fat-not by boiling the solids with from three to six successive quantities of ether, but by exhausting them in Soxhlet's apparatus-the conditions are somewhat changed. You will remember that $\mathrm{Mr}$. Hehner, in his paper, $r \in a d$ before our Society in the month of March, last year, pointed out, that extracting the milk solids in Soxhlet's apparatus yields about 0.2 per cent. more fat than boiling out with ether. I have reason to believe that the difference will be still larger, if not Soxhlet's apparatus only, but Soxhlet's method is applied, which consists in drying up the milk with plaster of Paris and exhausting the dry powder.

Dr. Dupré said the paper did not show that the standard of solids not fat required to be lowered below 9 as there was only one case which was below that figure. He supposed each figure referred to the milk from a number of cows, and asked if Dr. Vieth could add to the tables the maximum and minimum for single cows. He himself never got into difficulty with the standard of 9 where there was a number of cows.

Mr. Piesse said he thought they ought to feel very gratified that the averages in the tables bore out the standards of the Society, and no doubt they were extremely valuable, but he did not see how they were to apply them in the teeth of the results obtained, and acted upon by the Somerset House Chemists, who apparently derived those results from analyses made upon milk drawn from a single cow.

Mr. Hehner said he did not think that in fixing standards they had anything to do with the Somerset House Chemists, who should be left out of the question altogether in a scientific discussion. All they had to do was to arrive at the truth. He found that Dr. Vieth's results bore out the formula which he proposed some time ago, and he gave one or two illustrations to show this.

Mr. Piesse said he had made a great number of milk analysos since Mr. Hehner's paper was published and generally found them agree.

The President said he differed from Dr. Vieth in respect of the necessity for altering the standards, and especially looking at Tables II. and III., because if Table II., acknowledged to be milk picked from the best dairies, was correct, the standard adopted by the Society was on the arerage about 15 per cent. too low, while if the worst dairies were taken, Table III., the standard was about $3 \frac{1}{2}$ to 4 per cent. too low; thus one farmer might water to $3 \frac{1}{2}$ per cent. and the other to 15 per cent. without transgressing the limit of the Society. As they all knew a deficiency of $\cdot 2$ or $\cdot 3$ per cent. in solids not fat would not be noticed further than to say that the milk was poor, and he thought the lowering of the standard for that would be a wrong thing to do. As to Somerset House he personally had nothing to say, and quite agreed with Mr. Hohner that that question should be left out of a scientific discussion. He thought Dr. Vieth's figures strongly proved that the Society erred on the safe side when the standard of solids not fat was fixed. As to the fat, Dr. Vieth would wish to see that standard slightly raised, and no doubt the figures bore the reasoning out consideralily. With a large company, distribution meant a regular organised system when the churns were not out probably more than three or four hours and the cream did not separate, but in the case of men who only did one or two churns a day and these were perhaps out for six or eight hours, then he thought the separation of the cream might take place, but he hardly saw his way at the moment to suggest an increase in the fat standard. 
Dr. Dupré asked if any Public Analyst took 2.5 for fat and ever got convictions.

The President and Mr. Hehner both replied that they had done so.

Mr. Dyer said that one thing ought to be kept more in mind than it was, and that was that when the solids not fat in natural milk was low, the fat was unusually high, not in proportion but in a much greater proportion. Some time ago he brought before the Sreiety a large number of milk analyses undoubtedly genuine and taken all through the summer season, and in those the solids not fat rarely reached 9 , and sometimes was as low as 8.5 , but they were rich in cream, the percentage running up to 4.5 and 5.0 .

Dr. Vieth, in reply to Dr. Dupré, said he could not give the maximum and minimum solids not fat of single cow's milk, but only of the mixed milk of several cows. With regard to rich and poor milk, it was certainly to be talsen into consideration that the rich milks in Table II. came from farms where Jersey cows only, or a great number of them, were kept ; while the milks in Table III. came from farms where other cows were kept. With regard to the solids, as he had said in his paper, it depended very much whether they were boiled with ether or exhausted in Soxhlet's apparatus. Where the fat was properly extracted he was sure that in many cases the solids not fat would be below 9 per cent. 